\title{
膜および膜以外の除去素材を組み合わせた溶質除去一災害時にも 対応可能な携帯型血液浄化システム
}

\author{
山下明泰 \\ 湘南工科大学 工学部 人間環境学科 \\ 干 251-8511＼cjkstart神奈川県藤沢市辻堂西海岸 1-1-25
}

\section{Solute Removal by Combining Membrane and Other Devices - Wearable Artificial Kidney (WAK) System Available even under the Crisis}

\author{
Akihiro C. Yamashita \\ Department of Human Environmental Sciences, Shonan Institute of Technology \\ 1-1-25, Tsujido-Nishikaigan, Fujisawa, Kanagawa 251-8511, Japan
}

Hemodialysis is by far the most popular treatment modality for kidney disease patients in which blood and washing solution (called dialysate) are separating flowing on either side of the separation membrane in order to remove waste substances mainly due to concentration gradient. This treatment, however, requires not only membrane devices (dialyzers) but also electric power source, computer-controlled high-tech dialysis machine, more than $120 \mathrm{~L}$ of dialysate, and cannot be performed when the crisis occurs. We have been developing a wearable blood purification system by combining membrane and other devices. The first system included particles of adsorbent dispersed in agar gel and it removed toxic substances as long as 1 week; however, the direct contact of blood with agar may induce bioincompatible reactions. The second and third systems included an ultrafilter and an adsorbent that connected to the outside loop of the ultrafilter with various returning points of ultrafiltrate. Ultrafiltration naturally occurs due to pressure gradient from blood compartment to the outer lumen of the membrane and the ultrafiltrate returns back to the main blood stream by virtue of the connection. Both systems showed the solute removal performances with satisfactory results. Moreover, this system may be further developed to the system with no electric power source, water, or pump that can be available even under the crisis.

Key words : blood purification therapy / wearable artificial kidney (WAK) $/$ diffusion $/$ ultrafiltration $/$ adsorption

1.はじめに

腎㵴の機能が低下すると，やがて腎臟移植や各種

Tel: 0466-30-0234

Fax: 0466-30-0234

E-mail: yama@la.shonan-it.ac.jp
の血液浄化治療を受ける必要がある. 後者により加 療中の患者は，2010年度末現在，わが国にはおよそ 30 万人いる ${ }^{11}$. ほとんどの血液浄化治療は膜分離法 の応用であり, わが国では腎不全患者の 90\%以上が 拡散分離を利用した血液透析（Hemodialysis; HD） で治療を受けている. これは 1 回 4 時間, 週 3 回, 病 院で受ける治療である.この治療にはコンピュータ 


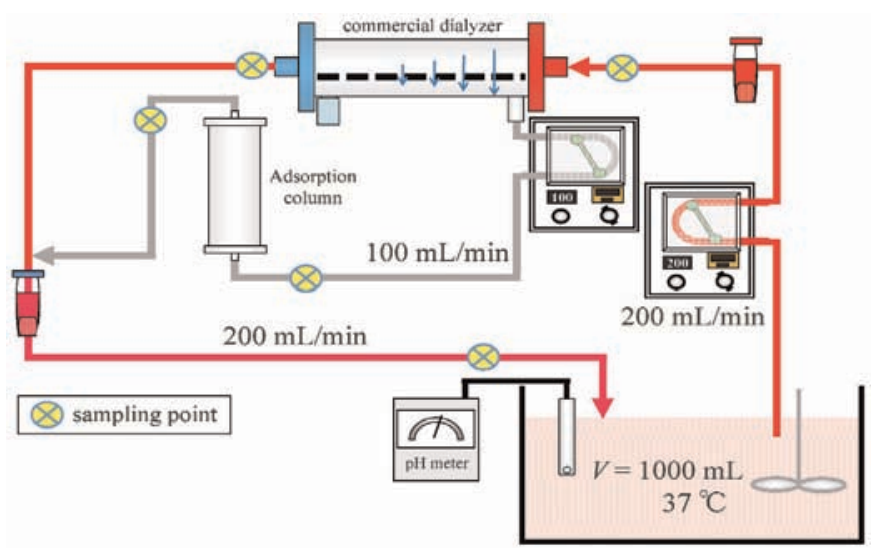

Fig. 1 Original system \#1

Ultrafiltrate is returned directly to the venous blood stream after cleaned.

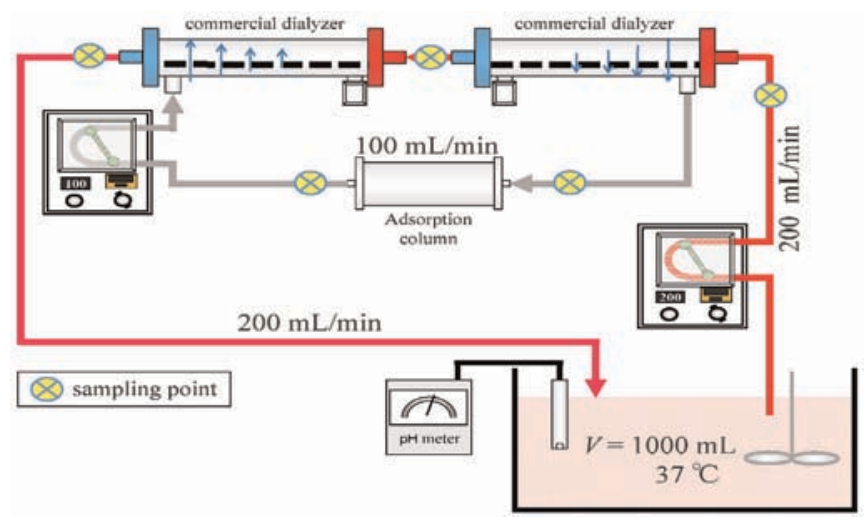

Fig. 2 Original system \#2

Two dialyzers are connected in series where one is used for positive and the other for reverse ultrafiltration.

制御された大型の透析装置（患者監視装置），および これに必要な電源とともに, $120 \mathrm{~L}$ 強の透析液が必要 である，そのため，この治療は必要なインフラスト ラクチャー（電源，水道水）が確保できる地域での 施行が前提となる。わが国には，通常，これが問題 になる地域はないが，大災害の発生時に極めて困難 な状況を目の当たりにしたことは記憶に新しい。本 報告では，分離膜と膜以外の素材を組み合わせて治 療システム全体を携帯化することで，大災害時にお いても利用可能な新しい血液浄化法を提案する.

\section{2. 通常の血液浄化治療に必要な装備}

現行の血液透析治療には, 中空糸型人工腎臓装置 （使い捨て透析器および血液回路）、コンピュータ制 御の患者監視装置， 120 L強の透析液を使用する。ま た，医薬品として認可された透析液原液の希釈液に

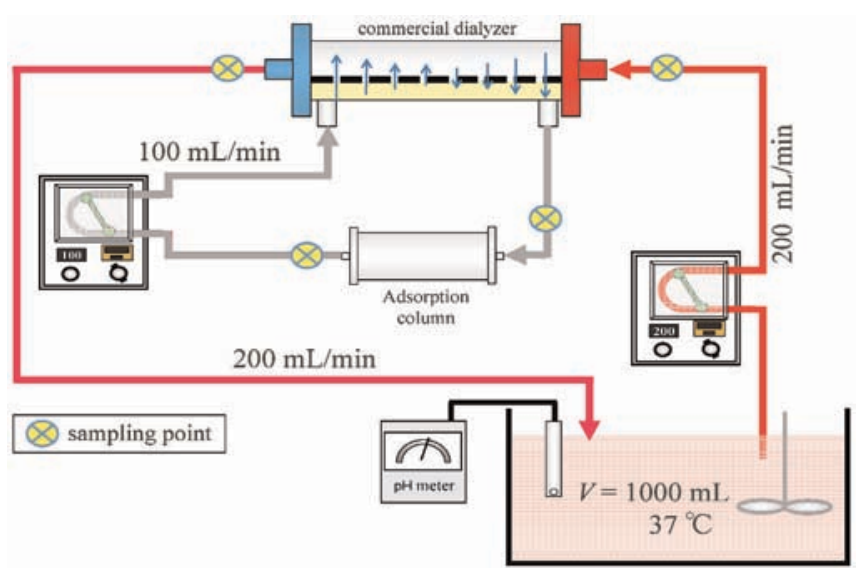

Fig. 3 Original system \#3

One dialyzer is used where the positive and reverse ultrafiltrations are occurring at the same time.

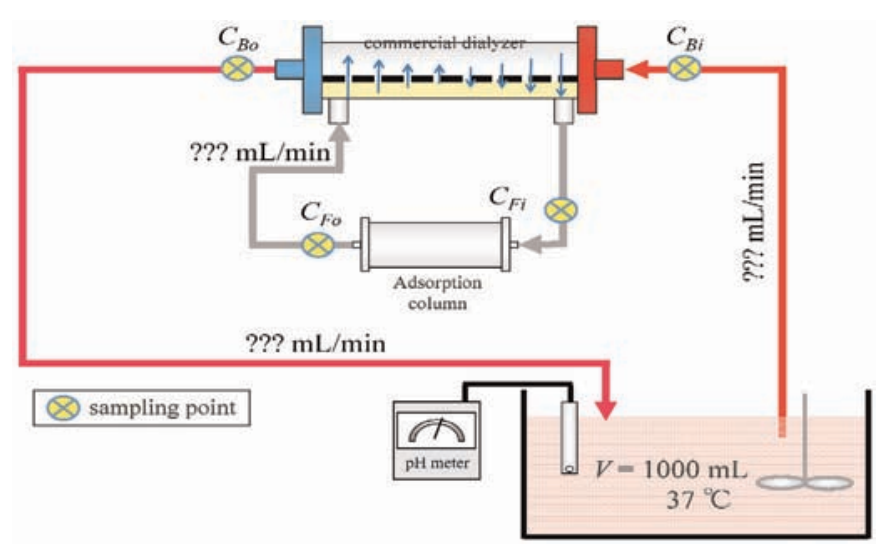

Fig. 4 Original system\#4

No pumps and no dialysate are necessary to clean the blood.

は逆浸透（RO）水を使用しなければならないが，水 道水から軟水化（イオン交換樹脂）装置，活性炭を 経由して RO 装置に接続する水処理の工程はかなり大 がかりである. 透析器は膜工学の進歩により, 特に わが国に扔いて高性能化が著しく, 中空糸内径 200 $\mu \mathrm{m}$, 全長 $30 \mathrm{~cm}$ 弱, 直径 $4 \mathrm{~cm}$ の筒型（家庭用懐中 電灯程度）サイズで成人の治療に十分な $1.5 \mathrm{~m}^{2}$ 強の 膜面積を確保できる. 透析膜は石油由来の合成高分 子素材を利用したものが多く，特にポリスルフォン およびポリエーテルスルフォンを主たる素材とする 膜が市場の $60 \%$ 以上を占めている. 治療に要求され る膜の性能は, 限外濾過用のそれに相当する。一方, 患者監視装置は一層の高機能化・複雑化が進んでい るため，エレクトロニクス技術の進歩にもかかわら ず，持ち運べるほどに小型軽量化はされていない （日本で開発されたマシンは，外国製の装置に較べて 小型で高性能である)。電源の確保と並んで, 水処理 


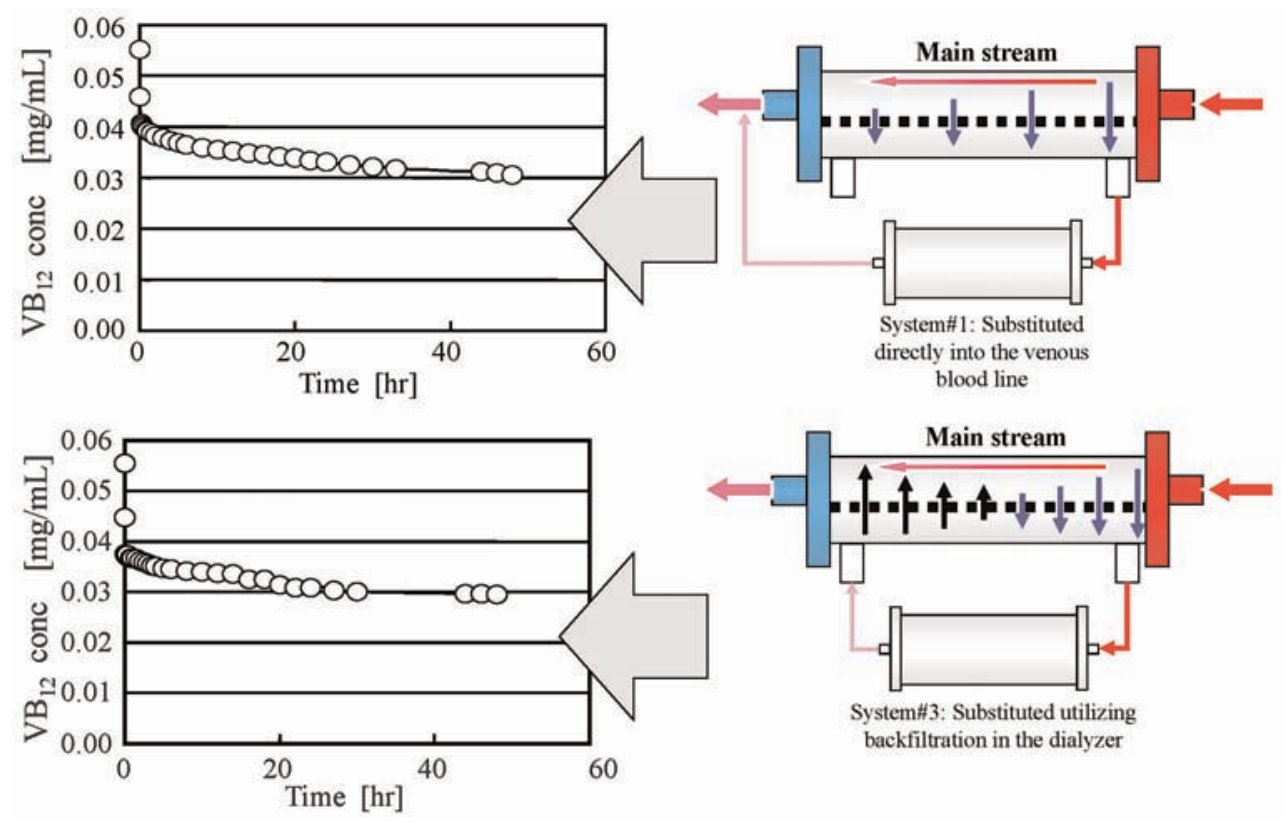

Fig. 5 Comparison of systems \#1 \& \#3 in removal of vitamin $B_{12}$.

システムや $120 \mathrm{~L}$ 強の透析液を持ち運ぶことはできな いので, 現行システムをそのまま小型軽量化するこ とはできない2．

\section{3. 携帯型血液浄化治療システム}

透析器には高性能限外濾過膜が使用されているの で，これを用いれば全血から血漿水のみを分離（限 外濾過）することができる。この血漿水は低分子量 タンパク質（アルブミン（分子量 66000）よりも小さ なタンパク質）を相当量含む電解質水溶液であり, 除去対象となる病因物質の多くはこの中に存在する. したがってこれを連続的にすべて廃棄し，濾過量に 見合う補充液 (医薬品, およそ $20 \mathrm{~L}$ ) を連続的に加 える治療もある。この方法は血液濾過法 （Hemofiltration; HF）とよばれるが，この場合にも補 充液のほかに，大型の制御装置が必要である。また 血漿水を透析したのでは，血液透析の場合同様， 120 Lの透析液と大型の制御装置が必要となる. そこで, 透析用水の削減を目指して，吸着材と寒天ゲルを組 み合わせたシステムを考案した ${ }^{3 \sim 5)}$ 。これは実験系 では有用なシステムであることが分かったが，血液 とゲルが直接接触することで血液成分に損傷を与え ることが問題と考えられた。次に，血液から血漿水 を分離し, この血漿水に対して吸着材（活性炭など） を使用して溶質を除去するシステムを構築した。浄 化後の血漿水を血液本体流に戻せば，専用の補充液 の使用を回避できる（システム 1, Fig. 1). しかしこ のシステムでは吸着材から流出する微粒子が流血を
介して体内に流入する可能性があり，これが血管を 傷つけたり, 閉塞する可能性がある。そこで, 透析 器をもう1本直列に接続して，1本目で得た血漿水を 吸着材などで浄化したのち 2 本目の透析器で逆向きの 濾過をかけて, 血液本体流に戻す（補充する）シス テムを開発した (システム 2, Fig. 2). しかし透析器 を 2 本使うことは, 経済的な意味で実用性が低いので, 1本の透析器の上流で正濾過, 下流で逆濾過が起こる ことを期待してコンパクトに改良した（システム 3 , Fig. 3) ${ }^{6}$. このシステムで中空糸内を流れる血液の圧 力損失を計算すると, 透析器の外部側にポンプがな くても同様な現象が起こることが期待できる.さら に体外循環を血圧で行うことができれば，このシス テムは完全ポンプレス, すなわち電源も補充液も必 要としない携帯型血液浄化システムに発展させるこ とも可能である（システム 4 , Fig. 4).

\section{4. 実験結果および考察}

Fig. 5 にはビタミン $\mathrm{B}_{12}$ （分子量 1355）を使用した 水系実験において, システム 1 とシステム 3 を比較し た結果を示した。血液側本体の流量は $200 \mathrm{~mL} / \mathrm{min}$, 濾過側の流量は $100 \mathrm{~mL} / \mathrm{min}$ とした. いずれのシステ ムを使用しても，ほぼ同じ溶質除去効率が期待でき ることがわかる，溶質除去性能が同じであれば，微 粒子が流血中に混入する危険性がないシステム 3 が, 安全性と経済性の両面に優れているといえる.

Fig. 6 には透析器を 2 本使用するシステム 2 を 1 本 で行うシステム 3 の結果と比較した。 ここでも実験結 


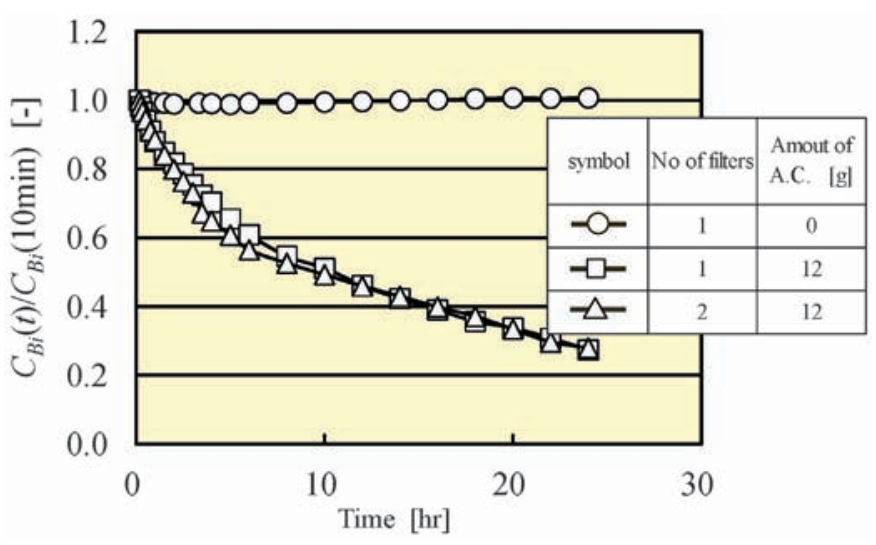

Fig. 6 Comparison of number of filters in the system in removing creatinine in bovine blood system. Time course of creatinine concentrations are normalized to those of $15 \mathrm{~min}$. A.C. - Activated Charcoal.

果はほぼ完全に一致している，すなわち，1本の透析 器の上流で正濾過，下流で逆濾過が起こることを期 待したシステム 3 が機能しており, 完成形に最も近い と考えられる。

Fig. 7 には透析器の外側を流れる限外濾液 (血漿水) 流量を変化させた場合の実験結果を，体外循環用以 外のポンプを使用しないシステム 4 (ポンプレス）と 比較した結果を示した．現行のシステム 4 は，血漿水 流量を $2 \mathrm{~mL} / \mathrm{min}$ としたときよりも僅かに高い性能を 示すことがわかった．透析器の中空糸内の圧損を高 め, 中空糸外側のループ部分の圧損を小さくするこ とで，さらに大きな限外濾過流量を確保できれば, 体外循環用ポンプさえ必要としない, 真のポンプレ ス装着型血液浄化システムを実現できる可能性もあ る.これは血液浄化治療のためのインフラストラク チャーが整っていない地域，あるいは災害等により， 一時的にインフラストラクチャーが破壊された場合 にも実施可能な治療となる。

\section{5. 結 論}

透析器内で生じる正濾過と逆濾過を吸着材などと 組み合わせることで, ポンプレスな装着型血液浄化 システムを実現できる可能性がある。このシステム は, 高純度の治療用水や電源の確保が難しい地域ば かりでなく, 大災害時における治療の確保に有用で ある，さらに，家庭での血液浄化療法を促進するこ とで, 社会復帰の促進や医療費の大幅な削減も期待 できる．本報告で提案したシステムとよく似たシス テムが，ここ数年，海外の医学関連雑誌に紹介され ていることは興味深い7,8).

大災害時には，身体の一部の組織が家具や建造物

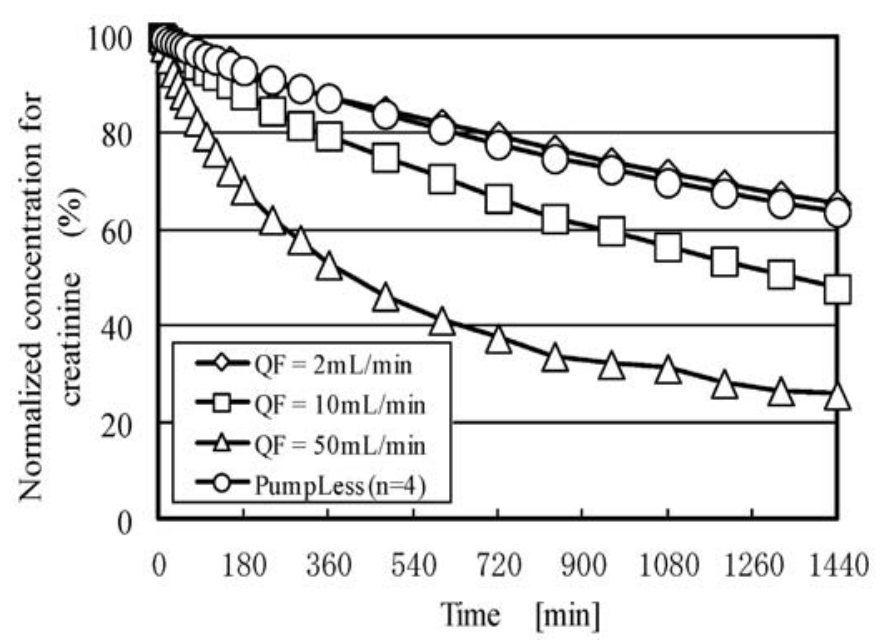

Fig. 7 Comparison of creatinine removal under four ultrafiltrate flow rates.

に挟まれ，圧迫されることもある。このような被害 者は, 救助された直後は軽傷に見えることが多いが, 圧迫を受けていた身体組織が解放されると, 組織内 に貯留していた成分や細胞内の成分が，一気に血液 中に放出されて, 重篤な症状を引き起こすことがあ る (Crush syndrome, 座滅症候群)。このような場合 にも血液浄化治療が必要であるが，大災害下では， 装置はもちろん電源や治療用水などのインフラスト ラクチャーが整わない，そのような場合にも，ここ で提案した簡便な装着型血液浄化装置が利用できる 可能性がある.

\section{文献}

1) 日本透析医学会統計調査委員会 : わが国の慢性腎不全 患者の現況（2010年 12 月 31 日現在）, p.4, 平成 23 年 6 月, 日本透析医学会

2) Davenport A, Gura V, Ronco, et al. : A wearable haemofiltration device for patients with end-stage renal failure: a pilot study, Lancet, 370, 2005-2010 (2007)

3) 山下明泰, 崎山亮一 : 寒天ゲルを用いた携帯型人工腎 臓の基礎検討，人工臓器， 26 巻 2 号，429-432 (1997)

4) 山下明泰, 崎山亮一, 山口清和, 東條角治 : 分離膜を 使用しない携帯型血液浄化装置の開発, 化学工学論文 集, 24 巻 2 号, 233-237 (1998)

5) Yamashita A, Sakiyama R, Hamada H, Tojo K : Control of rate of solute transport in newly developed portable agar gel blood purification system, Home Hemodial Int., 2, 6770 (1998)

6) 山下明泰 : 災害時における腎不全症例と人工腎臓，特 集「人工藏器と救急・集中治療」, 人工臓器, 37 巻 1 号, 62-66 (2008)

7) Stephens RL, Jacobsen SC, Atkin-Thot E, et al. : Portable/wearable aritificial kidney (WAK), Proc. Eur. Dial. Trans. Assoc., 12, 511-518 (1975) 
8) Gura V, Ronco C, Nalesso F, et al. : A wearable hemofilter for continuous amulatory ultrafiltration, Kidney Int., 73, 497-502 (2008)

(Received 26 October 2011;

Accepted 4 December 2011)

著者略歴

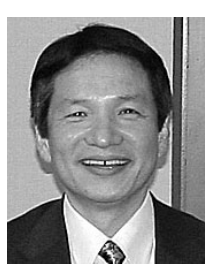

山下 明泰（やました あきひろ）

1980 年 3 月 早稲田大学理工学部 応用化学科卒業

1980 年 4 月 早稲田大学 助手. 北里大学 講師 • (医) 善仁会研究部

1986年8月テキサス大学オース チン校大学院化学工 学科へ留学

1991年5月同大学院修了 (Ph.D.)

1991年7月九州工業大学情報工 学部 助手

1999年 4 月 湘南工科大学工学部 材料工学科 助教授

2004 年 4 月 同大マテリアル工学 科 教授

2009 年 4 月 同大人間環境学科 教授, 大学院材料工 学専攻 主任 